\section{Molecular characterization of Pseudomonas aeruginosa isolates from various clinical specimens in Khartoum/Sudan: Antimicrobial resistance and virulence genes}

Islam A. Babour ${ }^{1}$, Maha B. Mohamed ${ }^{2}$, Asem A. Shehabi ${ }^{1}$

1 Department of Pathology-Microbiology and Forensic Medicine, The University of Jordan, School of Medicine, Amman, Jordan.

2 Department of Microbiology, The University of Medical Sciences and Technology, Faculty of Medical Laboratory Sciences, Khartoum.

Contact information:

Islam A. Babour.

Background: Pseudomonas aeruginosa is a pathogenic organism responsible for frequent wound and nosocomial infections worldwide. Its infections are difficult to control since the organism is known to rapidly develop antibiotic resistance and becomes multidrug-resistant (MDR) during treatment of patients.

Aim of the study: This study was intended to investigate the occurrence of certain important types of (ESBL) and (MBL) enzymes in association with important specific virulence factors associated with $P$. aeruginosa clinical isolates from Khartoum, Sudan.

Methods: This study investigated $70 P$. aeruginosa isolates which were collected from patients admitted to four major hospitals in Khartoum (Fedail, Ribat, Ibn Sina and Soba hospitals). These isolates were recovered from 40 wound swabs (57.1\%), 27 urine samples (38.6\%), and 3 pleural fluid samples (4.3\%) of patients. Higher numbers of isolates were recovered from males $42(60 \%)$ than in females 28 (40\%). All $P$. aeruginosa isolates were first confirmed by conventional biochemical and second using molecular PCR tests. PCR methods were also used for detecting the presence of the virulence genes ToxA, AlgD, LasB, exoS, exoU, CTX, GES-1, and genes of VIM, IMP, KPC, CTX, VEB-1 and SHV-1.

Results: Antimicrobial susceptibility testing of $P$. aeruginosa isolates showed a high resistance to azetronam 49 (70\%), followed by ceftazidime 32 (45.7\%), 16 ciprofloxacin (22.9\%), gentamicin 13 (18.6\%), 
piperacillin-tazobactam 11 (15.7\%), amikacin 9 (12.9\%), and imipenem $6(8.6 \%)$ showed the least resistance. All isolates were positive for algD and lasB (100\%), followed by toxA (90\%), exos (34.3), exoU (24.3\%), respectively. The rates of detected ESBL genes blaTEM, blaCTX-m, blaSHV-1,GES-1, were 3.3\%, 6.6\%, 10\%, 3.3\%, 10\%, respectively, but all isolates were negative for bla-KPC and bla- VIM and IMP. The percentages of pigment production were $61.4 \%$ for pyocyanin, $37.1 \%$ for pyoverdin and $1.4 \%$ for pyorubin.

Conclusion: The study demonstrated high rates of antimicrobial resistance markers to most commonly used antibiotics in treatment of $P$. aeruginosa infections. The majority of the isolates from urine and wound samples carried at least three potential virulence factor genes of algD, las $B$ and tox $A$ and without any significant relation to their antimicrobial resistance markers.

\section{Keywords}

Pseudomonas Aeruginosa; Antimicrobial Resistance; Virulence Factors;

Khartoum; Sudan.

\section{Introduction}

Pseudomonas aeruginosa is an opportunistic pathogen. The organism is frequently causes nosocomial infection, wound sepsis, pneumonia and urinary tract infections (UTIS) in hospitalized patients, especially in intensive care units (ICUs) [1-5].

$P$. aeruginosa needs very limited nutritional requirements. It can survive in distilled water [6]. The organism survives at wide range of temperature (4-42 $\left.{ }^{\circ} \mathrm{C}\right)$, and it is also tolerant to disinfectants and high concentrations of salts [7]. P. aeruginosa is capable of producing several different pigments, which are pyocyanin (blue), pyoverdin (yellow and fluorescent), pyorubin (red), and pyomelanin (brown) [8].

Multidrug-resistant $P$. aeruginosa is considered to be a serious problem in all types of infections because the organism has intrinsic resistance to several drug classes and it is able to acquire resistance to most normally effective anti-Pseudomonal drugs within a short period [9].

There are many virulence factors that may contribute to pathogenic potential of $P$. aeruginosa, such as elastase, alkaline protease hemolysins (phospholipase and lecithinase) and pyocyanin diffusible pigment. In addition, most $P$. aeruginosa strains produce a variety of toxins especially exotoxin encoded by the tox $A$ gene, which inhibits protein biosynthesis and is responsible for tissue necrosis. Exoenzyme $S$ is encoded by the exoS gene, which is secreted by a type-III secretion system directly into the cytosol of host epithelial cells and subsequently causes their destruction [10]. Other important virulence factor found in $P$. aeruginosa include $\operatorname{alg} D$, which codes for GDP mannose dehydrogenase, which is transcriptionally activated in mucoid strains, and elastase B, a zinc metallopro- 
tease encoded by the (lasB) gene, which attacks eukaryotic cells [11-12]. P. aeruginosa may also possess flagellae and pili, which helps in motility and adherence to host cells [13].

In recent years, a new variety of $\beta$-lactamases have been detected in $P$. aeruginosa clinical isolates. Broad spectrum $\beta$-lactam resistance attributed to $\beta$-lactamases is generally due to the metallo- $\beta$ lactamases (MBLs) such as IMP and VIM. The over expression of chromosomally encoded cephalosporinase, $A m p C$, is prevalent in $P$. aeruginosa. These MBLs hydrolyze anti-Pseudomonal cephalosporins and carbapenems effectively and their activity is not suppressed by the $\beta$-lactamase inhibitors that are currently available for treatment [14-15].

This study aimed to investigate $P$. aeruginosa isolates obtained from various clinical specimens of patients in Khartoum, Sudan, for their antimicrobial resistance profile, the occurrence of most important MBL genes and the common specific virulence factors using PCR molecular and culture tests.

\section{Materials and Methods}

This study included a total of 70 different clinical $P$. aeruginosa isolates collected from patients admitted to four hospitals in Khartoum, Sudan, during the period between September to November 2017. All patients were on treatment with various antibiotics.

The data about each patient was obtained and registered as the following: name, gender, age, and type of specimen, and all patients are agreed for any necessary medical process once they are admitted to each hospital.

\section{Culture and isolation}

All $P$. aeruginosa isolates were preserved in cryo tubes containing brain heart infusion with $15 \%$ glycerol samples and transported from Sudan to Jordan. All isolates were then subcultured on Pseudomonas Agar plates and incubated for 24 to 48 hours at 37
${ }^{\circ} \mathrm{C}$, and were examined for the presence of pigmentation and grape-like odor of $P$. aeruginosa at the research laboratories of the School of Medicine, The University of Jordan, Amman, Jordan.

\section{Identification and storage}

All growth of $P$. aeruginosa isolates was first identified using conventional biochemical tests including oxidase test, develop pigmention and growth on 42 ${ }^{\circ} \mathrm{C}$ and produce no chemical reaction during culture in Kligler's iron agar tube were stored in cryo tubes at $-70^{\circ} \mathrm{C}$.

\section{Antimicrobial susceptibility using disc diffusion method}

Antimicrobial susceptibility using disc diffusion test was performed according to the guidelines of the Clinical Laboratory and Standards Institute (CLSI, 2016) [16].

\section{Minimum inhibitory concentration (MIC) using E-test}

This test was only performed on the $P$. aeruginosa isolates, which were MDR to three or more antibiotic classes. Four classes of antibiotics were tested (ceftazidime, ciprofloxacin, imipenem and amikacin). Results were interpreted according to the CLSI 2016 guidelines [16].

\section{DNA extraction and PCR}

The DNA extraction was performed according to the Promega kit (USA). Two PCR assays were performed to confirm the isolates; one is specific for the genus Pseudomonas, while the other is specific for $P$. aeruginosa. Two pairs of primers were used for each assay based on 165 ribosomal DNA (rDNA) sequence as shown in Table 1.

The bacterial plasmid of freshly cultured $P$. aeruginosa isolates was extracted according to manufacturer instructions using the Zyppy TM Plasmid Miniprep Kit (QIAGEN, Germantown, MD, USA)for detection of ESBLs, MBLs and virulence genes. All 
Table 1. 16S rDNA primers sets for differentiation of P. aeruginosa from Pseudomonas species and their sequences and product size.

\begin{tabular}{|l|l|l|c|c|}
\hline \multicolumn{1}{|c|}{ Target } & Primer & Primer sequence (5' to $\left.\mathbf{3}^{\prime}\right)$ & Product size(bp) & Reference \\
\hline Pseudomonas species & PA-GS-F & GACGGGTGAGTAATGCCTA & 618 & 17 \\
& PA-GS-R & CACTGGTGTTCCTTCCTATA & & 17 \\
\hline & PA-SS-F & GGGGGATCTTCGGACCTCA & \multirow{2}{*}{956} & 17 \\
\hline
\end{tabular}

Table 2. Primer targets, sequences and their product size for five ESBLs and virulence genes.

\begin{tabular}{|c|c|c|c|c|}
\hline Target & Primer & Primer sequence ( $5^{\prime}$ to $\left.3^{\prime}\right)$ & Product size (bp) & Reference \\
\hline blaCTX-M & $\begin{array}{l}\text { CTX-M(F) } \\
\text { CTX-M(R) }\end{array}$ & $\begin{array}{l}\text { CGCTTTGCGATGTGCAG } \\
\text { ACCGCGATATCGTTGGT }\end{array}$ & 550 & 18 \\
\hline blaTEM & $\begin{array}{l}\text { TEM-A } \\
\text { TEM-B }\end{array}$ & $\begin{array}{l}\text { ATAAAATTCTTGAAGAC } \\
\text { TTACCAATGCTTAATCA }\end{array}$ & 1,075 & 19 \\
\hline blaVEB-1 & $\begin{array}{l}\text { VEB-FOR } \\
\text { VEB-REV }\end{array}$ & $\begin{array}{l}\text { CGACTTCCATTTCCCGATGC } \\
\text { GGACTCTGCAACAAATACGC }\end{array}$ & 642 & 19 \\
\hline blaSHV-1 & $\begin{array}{l}\text { SHV-FOR } \\
\text { SHV-REV }\end{array}$ & $\begin{array}{l}\text { TGGTTATGCGTTATATTCGCC } \\
\text { GCTTAGCGTTGCCAGTGCT }\end{array}$ & 867 & 20 \\
\hline blaGES-1 & $\begin{array}{l}\text { GES-1(F) } \\
\text { GES-1(R) }\end{array}$ & $\begin{array}{l}\text { ATGCGCTTCATTCACGCAC } \\
\text { CTATTTGTCCGTGCTCAGG }\end{array}$ & 864 & 21 \\
\hline blalMP & $\begin{array}{l}\text { IMP-A } \\
\text { IMB-B }\end{array}$ & $\begin{array}{l}\text { GAAGGCGTTTATGTTCATAC } \\
\text { GTACGTTTCAAGAGTGATGC }\end{array}$ & 587 & 22 \\
\hline blaVIM & $\begin{array}{l}\text { VIM2004A } \\
\text { VIM2004B }\end{array}$ & $\begin{array}{l}\text { GTTTGGTCGCATATCGCAAC } \\
\text { AATGCGCAGCACCAGGATAG }\end{array}$ & 382 & 22 \\
\hline blaKPC & $\begin{array}{l}\mathrm{KPC}(\mathrm{F}) \\
\mathrm{KPC}(\mathrm{R})\end{array}$ & $\begin{array}{l}\text { ATGTCACTGTATCGCCGTCT } \\
\text { TTACTGCCCGTTGACGCCCA }\end{array}$ & 880 & 23 \\
\hline algD & $\begin{array}{l}\text { algDF } \\
\operatorname{algDR}\end{array}$ & $\begin{array}{l}\text { CGTCTGCCGCGAGATCGGCT- } \\
\text { GACCTCGACGGTCTTGCGGA }\end{array}$ & 313 & 24 \\
\hline lasB & $\begin{array}{l}\text { lasBF } \\
\text { lasBR }\end{array}$ & $\begin{array}{l}\text { GGAATGAACGAAGCGTTCTCCGAC } \\
\text { TTGGCGTCGACGAACACCTCG }\end{array}$ & 284 & 24 \\
\hline toxA & $\begin{array}{l}\text { toxAF } \\
\text { toxAR }\end{array}$ & $\begin{array}{l}\text { CTGCGCGGGTCTATGTGCC } \\
\text { GATGCTGGACGGGTCGAG-3 }\end{array}$ & 270 & 24 \\
\hline exos & $\begin{array}{l}\text { exoS1-F } \\
\text { exoS1-R }\end{array}$ & $\begin{array}{l}\text { TCTGAATTCTTCCAGGCGGGTGAACATCA } \\
\text { TTTAGATCTCACCCTGGTATCCAAGGCGA }\end{array}$ & 504 & 25 \\
\hline exoU & $\begin{array}{l}\text { exoU-F } \\
\text { exoU-R }\end{array}$ & $\begin{array}{l}\text { GGG AAT ACT TTC CGG GAA GTT- } \\
\text { CGA TCT CGC TGC TAA TGT GTT- }\end{array}$ & 428 & 26 \\
\hline
\end{tabular}

primers, sequences and their product size for detection of extended-spectrum- $\beta$-lactamases (ESBLs), metallo- $\beta$-lactamases (MBLs) and virulence genes were used according to references as shown in Table 2 [18-26].

\section{Statistic}

Data generated from the study were tabulated as Microsoft Excel sheet and uploaded to Statistical Package for Social Sciences (SPSS version 20). Isolates from clinical sources were calculated for the categorical data by Fisher's exact test, to deter- 
mine whether there are any statistical differences in comparison to type of antibiotic resistance and virulence factors. The level of significance was set at a p-value of 0.05 to test the hypothesis of no association; Fisher's exact test is used for small sample size.

\section{Results}

A total of $70 P$. aeruginosa isolates were included in this study, and these were recovered from 40 wound swabs (57.1\%), 27 urine samples (38.6\%), and 3 pleural fluid samples (4.3\%) of patients. Higher rate of isolates were recovered from males $42(60 \%)$ than in females $28(40 \%)$. Antimicrobial susceptibility testing showed a high to low resistance rates to azotreonam 49 (70\%), followed by ceftazidime 32 (45.7\%), ciprofloxacin 16 (22.9\%), gentamicin 13 (18.6\%), piperacillin-tazobactam $11(15.7 \%)$, amikacin 9 (12.9\%), and imipenem $6(8.6 \%)$ respectively. All isolates were positive for potential genes of algD and lasB (100\%), followed by toxA (90\%), exoS (34.3), exoU (24.3\%) respectively. The rates of detected ESBL genes blaTEM,blaCTX-m, blaSHV-1,GES-1, were 3.3\%, $6.6 \%, 10 \%, 3.3 \%$, and $10 \%$ respectively. However, all isolates were negative for bla-KPC and blaVIM and IMP genes. The percentages of pigment production were $61.4 \%$ for pyocyanin, $37.1 \%$ for pyoverdin and $1.4 \%$ for pyorubin. (Tables $\mathbf{3}, \mathbf{4}, \mathbf{5}$ \& 6)

\section{Discussion}

This study included $P$. aeruginosa isolated from different clinical specimens of patients whom were admitted for medical care at four major hospitals in Khartoum, Sudan. The majority of the isolates were recovered from wound swabs (57.1\%), followed from urine $(38.6 \%)$ and the least percentage was (4.3\%) from pleural fluid. The study shows that all isolates have $\beta$-hemolytic activity and are mostly
Table 3. Antimicrobial susceptibility of $70 P$. aeruginosa isolates.

\begin{tabular}{|l|c|c|}
\hline \multirow{2}{*}{ Antimicrobial agent } & \multicolumn{2}{|c|}{ Resistant Average } \\
\hline Azotreonam & no & $\%$ \\
\hline Ceftazidime & 49 & 70 \\
\hline Ciprofloxacin & 33 & 47 \\
\hline Gentamicin & 16 & 23 \\
\hline Piperacillin- tazobactam & 13 & 19 \\
\hline Amikacin & 11 & 16 \\
\hline Imipenem & 9 & 13 \\
\hline
\end{tabular}

Table 4. MICs of 29 MDR isolates.

\begin{tabular}{l|c|c|c|c|}
$\begin{array}{l}\text { Domains/ } \\
\text { Facets }\end{array}$ & $\mathbf{M I C}_{\mathbf{5 0}}$ & $\mathbf{M I C}_{\mathbf{9 0}}$ & $\begin{array}{c}\text { MIC } \\
\text { Range }\end{array}$ & $\begin{array}{c}\text { Breakpoints } \\
\text { for susceptible }\end{array}$ \\
\cline { 2 - 5 } & $\mu \mathrm{g} / \mathrm{ml}$ & $\mu \mathrm{g} / \mathrm{ml}$ & $\mu \mathrm{g} / \mathrm{ml})$ & $\mu \mathrm{g} / \mathrm{ml}^{*}$ \\
\hline Amikacin & 7.7 & 13.9 & $0.24->256$ & $\leq 16$ \\
Ceftazidime & 3.1 & 5.6 & $0.75->256$ & $\leq 8$ \\
\hline Imipenem & 2.3 & 4.1 & $0.38->32$ & $\leq 2$ \\
Ciprofloxacin & 2.4 & 4.2 & $0.19->32$ & $\leq 1$
\end{tabular}

Table 5. Incidence of Virulence genes

\begin{tabular}{|l|c|c|}
\hline $\begin{array}{c}\text { Among } 70 \text { P. aeruginosa } \\
\text { isolates Gene }\end{array}$ & \multicolumn{2}{|c|}{$\boldsymbol{P}$. aeruginosa isolates } \\
\hline AlgD & no & $\%$ \\
\hline LasB & 70 & 100 \\
\hline ToxA & 70 & 100 \\
\hline exoS & 63 & 90 \\
\hline exoU & 24 & 34.3 \\
\hline
\end{tabular}

Table 6. Shows distribution of EBLs genes, plasmid-mediated virulence genes of KPC and VIM2/IMP.

\begin{tabular}{|l|c|c|}
\multirow{2}{*}{\multicolumn{1}{c|}{ GENE }} & \multicolumn{2}{c|}{$\boldsymbol{P . ~ a e r u g i n o s a}$ isolates } \\
\cline { 2 - 3 } & no & $\%$ \\
\hline bla $_{\mathrm{TEM}}$ & 1 & 3.3 \\
bla $_{\mathrm{CTX}-\mathrm{M}}$ & 2 & 6.6 \\
\hline bla $_{\mathrm{SHV}-1}$ & 3 & 10 \\
bla $_{\mathrm{GES}-1}$ & 1 & 3.3 \\
bla $_{\mathrm{VEB}}$ & 3 & 10 \\
\hline KPC & 0 & 0 \\
\hline VIM2/IMP & 0 & 0 \\
\hline
\end{tabular}


producing pigmentation, either pyocyanin (61.4\%) or pyoverdin $(37.1 \%)$ and more rarely the pigment pyorubin (1.4\%).

Many studies have reported that most important virulence factors of $P$. aeruginosa are production of pigments, including mostly both pyoverdin and pyocyanin and blood hemolysis, which contribute to its pathogenicity during the infection process [27, 28]. However, there are few studies comparing the incidence of pyocyanin and pyoverdin production of $P$. aeruginosa isolates according to their clinical sources. It has been demonstrated that pyocyanin has numerous antagonistic effects and damages host tissues in vitro and in vivo, including pro-inflammatory and free radical effects [29].

Treatment of infections caused by $P$. aeruginosa has become challenging in recent years due to the ability of this pathogen to rapidly develop resistance to multiple classes of antibiotics. Therefore, the investigation of the genetics of antimicrobial resistance of this organism may help to control and treat its infections by selection of useful antibiotics [30].

This study also showed high to low rates of resistance markers to certain commonly used drugs in treatment of Pseudomonas infections including azotreonam (70\%), ceftazidime (47\%), ciprofloxacin (23\%), gentamicin (19\%), piperacillin-tazobactam (16\%), amikacin (13\%) and imipenem (9\%) (Table 3). A previous study conducted also in Sudan [31], reported that

$P$. aeruginosa isolates from clinical samples of patients was $49.3 \%$. The study showed that 74 of the isolates were resistant to carbenicillin [31]. While a new study conducted in Sudan found a multidrugresistant (MDR) $P$. aeruginosa isolate from urine of patient with a urinary tract infection was highly resistant to many antibiotics including ciprofloxacin, gentamicin, ceftazidime, piperacillin, and meropenem [32].

The most important mechanisms of resistance to carbapenems are production of carbapenemase enzymes, which have the ability to hydrolyze penicillins, cephalosporins, monobactams and carbapenems. Carbapenem-resistant Klebsiella (KPC $\beta$-lactamases) hydrolyze most $\beta$-lactams, including carbapenems. [33, 34]. Therefore, early detection of this gene will help to avoid incorrect treatment, controlling hospital infections, and preventing the increase spread of resistant strains in hospital and community [35].

The study didn't find any bla- VIM/IMP and KPC genes in $P$. aeruginosa isolates. Other mechanisms might be responsible for the resistance other than the $K P C$ genes. It is interesting to note here that similar results to ours have been recently reported by a Jordanian study [2].

The study has demonstrated that all $P$. aeruginosa isolates carried potential $A / g D$ and las $B$ genes $(100 \%)$, followed by other toxic genes (Table 6). All MDR isolates were highly associated with these virulence genes compared to less resistant isolates. However, no significant associations were found between antibiotic resistance markers and putative virulence genes neither among MDR nor all $P$. aeruginosa isolates from urine or wound samples $P$. aeruginosa excreted many virulence factors and forms biofilms that contribute to its infection process. Virulence of $P$. aeruginosa is multifactorial, involving both secreted and cell-associated bacterial products such as elastase, alkaline protease, protease IV, exotoxin A and exoenzymeS. However, most studies consider that exotoxin A, exoenzymes and exoenzymeU are major virulence factors produced by most clinical $P$. aeruginosa strains, and the most toxic effects of these factors are causing host tissue damage $[2,36]$.

\section{Conclusion}

This study demonstrated high rates of antimicrobial resistance markers to most commonly used antibiotics in the treatment of $P$. aeruginosa infections. There was no significant relationship discovered between antimicrobial resistance markers and 
potential virulence genes among all $P$. aeruginosa isolates including MDR isolates from either urine or wound samples.

\section{Acknowledgements}

The authors are thankful for the Scientific Research Deanship of The University of Jordan, Amman, Jordan for its financial support.

\section{References}

1. Shehabi AA, Haider AA, Fayyad MK., Frequency of antimicrobial resistance markers among Pseudomonas aeruginosa and Escherichia coli isolates from municipal sewage effluent water and patients in Jordan. IAJA 2011;1(1-8).

2. Al Dawodeyah HY, Obeidat N, Abu-Qatouseh LF, Shehab, $A A$, Antimicrobial resistance and putative virulence genes of Pseudomonas aeruginosa isolates from patients with respiratory tract infection. Germs 2018; 8(1), p.31.

3. Paling FP, Wolkewitz M., Depuydt P, De Bus L, Sifakis F, Bonten MJ. et al. 2017. P. aeruginosa colonization at ICU admission as a risk factor for developing P. aeruginosa ICU pneumonia. Antimicrob Resist Infect Control 2017; 6(1), p.38.

4. Harris AD, Jackson SS, Robinson G, Pineles L Leekha S Thom $K A$, et al. Pseudomonas aeruginosa colonization in the intensive care unit: prevalence, risk factors, and clinical outcomes. Infect Cont Hosp Epidemiol 2016; 37(5), 544-548.

5. Driscoll JA, Brody, SL, Kollef M.H. The epidemiology, pathogenesis and treatment of Pseudomonas aeruginosa infections. Drugs 2007; 67(3), pp.351-368

6. Shehabi AA, Masoud H, Balkam Maslamani FA. Common antimicrobial resistance patterns, biotypes and serotypes found among Pseudomonas aeruginosa isolates from patient's stools and drinking water sources in Jordan. J Chemother 2005; 17(2), pp.179-183.

7. LaBauve $A E$, Wargo, MJ. Growth and laboratory maintenance of Pseudomonas aeruginosa. Curr Protoc Microbiol 2012; 25(1),6E-1.

8. Persson, A., Study of Pseudomonas aeruginosa and different wound dressing products. Master of Science Thesis, Chalmers University Of Technology SE - 41296 Göteborg Sweden, 2010.

9. Mahmoud AB, Zahran WA, Hindawi GR, Labib AZ, Galal R . Prevalence of multidrug-resistant Pseudomonas aeruginosa in patients with nosocomial infections at a university hospital in Egypt, with special reference to typing methods. J Virol Microbiol 2013; 13, pp.165-59.
10. Rumbaugh KP, Griswold, JA, Hamood AN. Pseudomonas aeruginosa strains obtained from patients with tracheal, urinary tract and wound infection: variations in virulence factors and virulence genes. J Hosp Infect 1999; 43(3), 211-218

11. Toder DS, Ferrell SJ, Nezezon JL, Rust L. Iglewski BH. lasA and lasB genes of Pseudomonas aeruginosa: analysis of transcription and gene product activity. Infect Immun 1994; 62(4), 13201327.

12. Deretic V, Gill JF, Chakrabarty AM. Gene algD coding for GDPmannose dehydrogenase is transcriptionally activated in mucoid Pseudomonas aeruginosa. J bacteriol 1987; 169(1), 351358.

13. Crousilles A, Maunders E, Bartlet S, Fan C, Ukor EF , Abdelhamid $Y$, et al. Which microbial factors really are important in Pseudomonas aeruginosa infections?. Fut Microb 2015; 10(11), 1825-1836.

14. Tam VH, Schilling AN, LaRocco MT, Gentry LO, Lolans K, Quinn JP. Prevalence of AmpC over-expression in bloodstream isolates of Pseudomonas aeruginosa. Clin Microbiol Infect 2007; 13(4), 413-418.

15. Bonomo RA, Szabo D. Mechanisms of multidrug resistance in Acinetobacter species and Pseudomonas aeruginosa. Clin infect Dis 206; 43(2), S49-S56.

16. Clinical Laboratory and Standards Institute (CLSI). Methods for dilution antimicrobial susceptibility tests for bacteria that grow aerobically; approved standard - tenth edition. CLSI document M07-1. A10 Villanova, PA, USA: CLSI,. 2016.

17. Spilker T, Coenye T, Vandamme P, LiPuma JJ. PCR-based assay for differentiation of Pseudomonas aeruginosa from other Pseudomonas species recovered from cystic fibrosis patients. J Clini Microbial 2004;42 (5):2074-2079.

18. Pitout JD, Chow BL,Gregson DB, LauplandKB., Elsayed, S. and Church, D.L.,2007. Molecular epidemiology of metallo- $\beta$ lactamase-producing Pseudomonas aeruginosa in the Calgary Health Region: emergence of VIM2-producing isolates. J Clin Microbiol 2007; 45(2), pp.294-298

19. Jiang $X$, Ni $Y$, Jiang $Y$, Yuan $F$, Han L, Li $M$, et al. Outbreak of infection caused by Enterobacter cloacae producing the novel VEB-3 beta-lactamase in China. J Clin Microbiol 2000; 43(2):826-31.

20. Fazeli N, Momtaz H. Virulence gene profiles of multidrugresistant Pseudomonas aeruginosa isolated from Iranian hospital infections. Iran Red Crescent Med J. 2014;18; 16 (12).

21. Shacheraghi F, Shakibaie MR, Noveiri H. Molecular Identification of ESBL Genes blaGES-1, blaVEB-1, blaCTX-M blaOXA-1, blaOXA-4, blaOXA-10 and blaPER-1in Pseudomonas aeruginosa Strains Isolated from Burn Patients by PCR, RFLP and Sequencing Techniques. W Acad Sci Eng Technol 2010; 4(1)2010.

22. Pitout JDD, Gregson DB, Poirel L, McClure J-A., Le P, Church DL. Detection of Pseudomonas aeruginosa Producing Metallo$\beta$-Lactamases in a Large Centralized Laboratory. J Clin Microbiol 2005; 43(7): 3129-3135. 
23. Akpaka PE, Swanston WH, Ihemere $\mathrm{HN}$, Ihemere $\mathrm{NH}$, Correa A, Torres A J. et al. Emergence of KPC-producing Pseudomonas aeruginosa in Trinidad and Tobago. J Clin Microbiol 2009;47(8):2670-1.

24. Wolska K, Szweda P. Genetic features of clinical Pseudomonas aeruginosa strains. Pol J Microbiol 2009;58:255-60.

25. Shaver CM, Hauser AR. Relative contributions of Pseudomonas aeruginosa ExoU, ExoS, and ExoT to virulence in the lung. Infect Immun 2004; 72(12), pp.6969-6977.

26. Mitov I, Strateva T, Markova B. Prevalence of virulence genes among Bulgarian nosocomial and cystic fibrosis isolates of Pseudomonas aeruginosa. Braz J Microbiol 2010; 41 (3):588595.

27. Das T, Manefield M. Pyocyanin promotes extracellular DNA release in Pseudomonas aeruginosa. PLoS ONE , 2012; 7, e46718

28. Lau GW, Hassett DJ, Ran H, Kong F. The role of pyocyanin in Pseudomonas aeruginosa infection. Tren Mol Med 2004, 10, 599-606.

29. Hall S, McDermott C, Anoopkumar-Dukie, S, McFarland AJ, Forbes A. Perkins AV. Cellular Effects of Pyocyanin, a Secreted Virulence Factor of Pseudomonas aeruginosa. Toxins 2016, 8, 236.

30. Lister PD, Wolter DJ, Hanson ND. Antibacterial-Resistant Pseudomonas aeruginosa: Clinical Impact and Complex Regulation of Chromosomally Encoded Resistance Mechanisms. Clin Microbiol Rev 2009;22(4):582-610.

31. Abd Elmageed, MD AAE. Molecular Characterization and Sensitivity Patterns of Pseudomonas aeruginosa among patients with Different Diseases, PhD Thesis., Sudan University of Sciences and Technology,2012.

32. Hussain M, Suliman M, Ahmed A, Altayb H, Elneima E. Draft Genome Sequence of a Multidrug-Resistant Pseudomonas aeruginosa Strain Isolated from a Patient with a Urinary Tract Infection in Khartoum, Sudan. Genome Announcements 2017;5(16):e00203-17. doi:10.1128/genomeA.00203-17.
33. Castanheira M, Deshpande LM, Costello A, Davies TA, Jones RN. Epidemiology and carbapenem resistance mechanisms of carbapenem-non-susceptible Pseudomonas aeruginosa collected during 2009-11 in 14 European and Mediterranean countries. J Antimicrob Chemother 2014;69,1804-1814.

34. Poirel L, Nordmann P, Lagrutta E, Cleary T, and Munoz-Price LS. Emergence of KPC-producing Pseudomonas aeruginosa in the United States. Antimicrob Agents Chemother 2010;54:3072.

35. Adler A, Navon-Venezia, S, Moran-Gilad J, Marcos E, Schwartz D, Carmeli Y. Laboratory and clinical evaluation of screening agar plates for detection of carbapenem-resistant Enterobacteriaceae from surveillance rectal swabs. J Clin Microbiol 2011;49: 2239 42.

36. Agnello $M$, Wong-Beringer $A$. Differentiation in quinolone resistance by virulence genotype in Pseudomonas aeruginosa. PLoS One 2012; 7:e42973

\section{Publish in The International Arabic Journal of Antimicrobial Agents}

The Journal is an open access peer-reviewed journal that publishes scientific papers about all aspects of antimicrobials. The journal will publish original research articles, reviews, brief reports and case reports dealing with basic and clinical antibacterial agents, antiviral, antiprotozoals, antituberculuous, antifungal and antihelminthes agents. All manuscripts must be prepared in English, and are subject to a rigorous and fair peer-review process. Accepted papers will immediately appear online. The journal aims to advance the knowledge, attitude and the research of chemotherapy in the Arabic world in cooperation with international, national scientific and public societies as well as research centers with similar aims and objectives. 